\title{
Regular Exercise Enhances the Immune Response Against Microbial Antigens Through Up-Regulation of Toll-like Receptor Signaling Pathways
}

\author{
Qishi Zhenga,b Guangying Cui ${ }^{\mathrm{a}}$ Jianing Chen ${ }^{\mathrm{a}}$ Hainv Gao ${ }^{\mathrm{a}}$ Yingfeng Wei ${ }^{\mathrm{a}}$ \\ Toshimitsu Uede ${ }^{c}$ Zhi Chen ${ }^{a}$ Hongyan Diao $^{a}$

\begin{abstract}
aState Key Laboratory for Diagnosis and Treatment of Infectious Diseases, Collaborative Innovation Center for Diagnosis and Treatment of Infectious Diseases, The First Affiliated Hospital, School of Medicine, Zhejiang University, Hangzhou, Zhejiang, China; 'bublic Sport Center, Department of Public Physical and Art Education, Zhejiang University, Hangzhou, Zhejiang, China; 'Molecular Immunology, Institute for Genetic Medicine, Hokkaido University, Sapporo, Japan
\end{abstract}

\section{Key Words}

Regular physical exercise $\cdot$ Pathogenic infection $•$ Cytokine $\bullet$ Toll-like receptor $•$ Immune response

\begin{abstract}
Background/Aims: Regular physical exercise can enhance resistance to many microbial infections. However, little is known about the mechanism underlying the changes in the immune system induced by regular exercise. Methods: We recruited members of a university badminton club as the regular exercise (RE) group and healthy sedentary students as the sedentary control (SC) group. We investigated the distribution of peripheral blood mononuclear cell (PBMC) subsets and functions in the two groups. Results: There were no significant differences in plasma cytokine levels between the RE and SC groups in the true resting state. However, enhanced levels of IFN- $\gamma$, TNF- $\alpha$, IL-6, IFN- $\alpha$ and IL-12 were secreted by PBMCs in the RE group following microbial antigen stimulation, when compared to the SC group. In contrast, the levels of TNF- $\alpha$ and IL- 6 secreted by PBMC in the RE group were suppressed compared with those in SC group following non-microbial antigen stimulation (concanavalin A or $\alpha$-galactosylceramide). Furthermore, PBMC expression of TLR2, TLR7 and MyD88 was significantly increased in the RE group in response to microbial antigen stimulation. Conclusion: Regular exercise enhances immune cell activation in response to pathogenic stimulation leading to enhanced cytokine production mediated via the TLR signaling pathways.

Q. Zheng and G. Cui contributed equally to this study.

Hongyan Diao, PhD\&MD

The First Affiliated Hospital, School of Medicine, Zhejiang University, 79 Qingchun Road, Hangzhou, Zhejiang, 310003, (China)

Tel. / Fax 86-571-87236446, E-Mail diaohy@zju.edu.cn
\end{abstract}

KARGER 125 


\section{Cellular Physiology Cell Physiol Biochem 2015;37:735-746 \begin{tabular}{l|l|l} 
DOI: 10.1159/000430391 & (C) 2015 S. Karger AG, Basel
\end{tabular} and Biochemistry Published online: September 11, $2015 \quad$ www.karger.com/cpb \\ Zheng et al.: Regular Exercise Boosts Immunity to Microbes}

\section{Introduction}

Physical activity includes exercise and other activities that involve bodily movement such as playing, working and recreational activities. Physical inactivity is related to high incidence of cancers, diabetes and ischemic heart disease. The World Health Organization (WHO) has reported that physical inactivity has been identified as the fourth leading risk factor for global mortality, causing an estimated 3.2 million deaths every year[1]. In other words, people who engage regularly in moderate exercise are often resistant to many diseases [2-5]. Some studies have shown that moderate exercise results in enhanced immunity and a decreased upper respiratory tract infection rate [6]. In contrast, exhaustive exercise can lead to reduced immunity, a high incidence of upper respiratory tract infections, and damage to erythrocytes [7-9]. Thus, any type of physical activity can influence the immune system, although these effects will often depend on the type of exercise and its duration.

Regular exhaustive exercise causes a significant reduction in the number of immune cells and disruption of leukocyte function and apoptosis. Furthermore, regular highintensity exercise can lead to decreased secretion of cytokines, such as interleukin (IL)6, tumor necrosis factor (TNF)- $\alpha$, interferon (IFN)- $\gamma$, IL-1 $\beta$, IL-2, IL-8 and IL-10 [10, 11]. Insufficient recovery between periods of prolonged exercise appears to exaggerate these effects [12]. These results indicate the immunosuppressive effects of excessive exercise, which, to some extent, explain the higher incidence of upper respiratory infections during the competition season. However, regular moderate exercise helps to reduce the risk of cardiovascular disease and breast cancer by boosting the immune system $[8,13]$. In elderly males, those who engage regularly in moderate exercise have differences in the CD4 ${ }^{+} / \mathrm{CD}^{+} \mathrm{T}$ cell ratio and the number of natural killer (NK) cells in the true resting state (i.e., more than $24 \mathrm{~h}$ after training) compared with those who do not exercise regularly [14]. These changes associated with moderate training may help reduce inflammation [15]. Also, aerobic exercise reduces the incidence and severity of upper respiratory tract infections [16]. Nevertheless, the mechanisms underlying the immune changes induced by regular exercise are not clear. Thus, in this study, we focused on the changes in the immune responses to a series of stimuli induced by regular exercise. We found that regular exercise improved the ability of the immune system to defend against the invasion of pathogens by producing substantial amounts of Th1-type and pro-inflammatory cytokines via the Toll-like receptor (TLR) signaling pathways. We propose that this mechanism explains, in part, why regular physical exercise enhances resistance to infection.

\section{Materials and Methods}

Subjects

Twenty college student volunteers (10 males and 10 females) belonging to the badminton club of Zhejiang University (China) and exercising three times a week ( $2 \mathrm{~h}$, with a 5 min break after each 30 min of exercise on each occasion), were recruited as the regular exercise (RE) group (Table 1). Twenty-five healthy sedentary college students (12 males and 13 females) were recruited as the sedentary control (SC) group (Table 1). All volunteers satisfied the following requirements: no exercise in the previous 3 days, no smoking, no previous medical record of cardiovascular or metabolic diseases, no recent symptoms of upper respiratory tract infection, and abstinence from any medication for at least 1 month before the study. The females all menstruated regularly. The duration of their periods ranged from 26 to 32 days. Blood was obtained from them in the follicular phase of their cycles (i.e., days 7-12). We measured plasma titers of Anti-streptolysin $\mathrm{O}$ (ASO) and Hepatitis B core antibody (HBcAb) in both groups (Table 1). The protocol was approved by the Ethics Committee of the First Affiliated Hospital of Medical College, Zhejiang University (China) (Reference number 2014-273). Written informed consent was received from all participants. Anticoagulant-treated blood samples were collected from volunteers after obtaining their informed consent. 


\section{Cellular Physiology Cell Physiol Biochem 2015;37:735-746 \begin{tabular}{l|l} 
DOI: 10.1159/000430391 & (c) 2015 S. Karger AG, Basel
\end{tabular} and Biochemistry Published online: September 11, 2015 www.karger.com/cpb \\ Zheng et al.: Regular Exercise Boosts Immunity to Microbes}

Table 1. Clinical features of the volunteers in the two groups. ${ }^{\mathrm{a}}$ Anti-streptolysin $\mathrm{O},{ }^{\mathrm{b}} \mathrm{Hepatitis} \mathrm{B}$ core antibody

\begin{tabular}{llll}
\hline & $S C(n=25)$ & $R E(n=20)$ & $p$ value \\
\hline Age (years) & $21.8 \pm 1.5$ & $20.8 \pm 2.1$ & 0.05689 \\
Males (\%) & $12(48 \%)$ & $10(50 \%)$ & 0.8676 \\
ASO positive & $2(8 \%)$ & $2(10 \%)$ & 0.7397 \\
HBcAb $^{\text {b }}$ positive & $0 / 25(0 \%)$ & $0 / 20(0 \%)$ & 1.00 \\
\hline
\end{tabular}

Isolation and culture of peripheral blood mononuclear cells

PBMCs were isolated by density centrifugation on Ficoll according to the manufacturer's instructions. Cells $\left(2 \times 10^{6} / \mathrm{ml}\right)$ were then cultured with ConA $(10 \mu \mathrm{g} / \mathrm{ml}$; Vector Laboratories, Burlingame, CA, USA $)$, $\alpha$-GC $(0.2 \mu \mathrm{g} / \mathrm{ml}$, Pharmaceutical Research Laboratories, Kirin Brewery, Gunma, Japan), heat-inactivated S. pyogenes $\left(2 \times 10^{7} \mathrm{CFU} / \mathrm{ml}\right.$; a clinical isolate (type M12/T12) from a patient with pharyngitis in Hokkaido University Hospital, Sapporo, Japan) [17], or hepatitis B core antigen (HBcAg) (HBV core 1-186 a.a., $2 \mu \mathrm{g} /$ $\mathrm{ml}$, PerSpec, NJ, USA) for $24 \mathrm{~h}$. Supernatants were collected and stored at $-80^{\circ} \mathrm{C}$. Harvested cells were frozen at $-80^{\circ} \mathrm{C}$ in TRIzol reagent (Invitrogen, Carlsbad, CA, USA) for total mRNA extraction.

\section{Flow cytometry}

The following monoclonal antibodies were used in the present study: fluorescein isothiocyanate (FITC)-anti-CD4 and phycoerythrin (PE)-anti-CD8/PerCP-anti-CD3, and PE-anti-iNKT (BD Pharmingen, CA, USA); FITC-anti-CD4, PE-anti-CD25, and FITC-anti-CD3/PE-anti-CD (16+56) (Invitrogen). PE-BDCA-1, PE-BDCA-2 and PE-BDCA-3 (Miltenyi, Germany). Cells were stained with the appropriate antibodies and incubated in $4^{\circ} \mathrm{C}$ for $30 \mathrm{~min}$ according to standard procedures. Flow cytometry was performed on the Beckman Coulter FC500 MPL (Beckman Coulter, Brea, CA, USA), and CXP software (Beckman coulter, CA, USA) was used for analysis.

\section{$A S O$ and $H B c A b$ detection}

The titers of ASO (Beckman coulter, CA) and HBcAb (Abbott, Abbott Park, Illinois) were measured using a standard clinical automatic analyzer.

ELISA

The levels of IFN- $\gamma$, TNF- $\alpha$, IL-6, IFN- $\alpha$ and IL-12 were detected by ELISA kits (eBioscience, San Diego, CA, USA) following the manufacturer's instructions.

\section{Analysis of mRNA expression}

Total RNA was isolated using TRIzol (Life Technologies, Gaithersburg, MD, USA) according to the manufacturer's instructions. The levels of TLR2, TLR4, TLR7, and MyD88 mRNA expression in different groups was determined by real-time quantitative PCR (qPCR) with an ABI Prism 7000 Sequence Detection System (Applied Biosystems-Life Technologies, Foster City, CA, USA) using GAPDH as an internal standard. The specific primers used were as follows: GAPDH, 5'-ATC CCA TCA CCA TCT TCC AGG-3' (sense), 5'-GAG CCC CAG CCT TCT CCATG-3' (anti-sense); TLR-2, 5'-TCA CTC AGG AGC AGC AAGCA-3' (sense), 5'-TGT GAC ATT CCG ACA CCG AGA-3' (anti-sense); TLR-4, 5' - AAT CCC CTG AGG CAT TTAGG-3' (sense), 5'- CAG GGC TAA ACT CTG GATGG-3' (anti-sense); TLR-7, 5'-AGC TTT AAC CTC TCG CCA TTACA-3' (sense), 5'-TTG AGC AGA AGC CAA CTT CACT-3' (anti-sense); MyD88, 5'-GCA CAT GGG CAC ATA CAGAC-3' (sense), 5'-GAC ATG GTT AGG CTC CCTCA-3' (anti-sense); STAT1, 5'-ATC AGG CTC AGT CGG GGA ATA-3' (sense), 5'-TGG TCT CGT GTT CTC TGT TCT-3' (anti-sense); STAT6, 5'-GTT CCG CCA CTT GCC AATG-3' (sense), 5'-TGG ATC TCC CCT ACT CGGTG-3' (anti-sense). Values for TLR2, TLR7, MyD88, STAT1 and STAT6 were normalized against those for GAPDH.

\section{Data analysis}

Data are presented as mean \pm SD and are representative of at least two independent in vitro experiments. The unpaired Student's t-test or Fisher's exact test, were used, as appropriate, for statistical analysis. Statistical significance was set at $P<0.05$.

\section{KARGER}




\section{Results}

No significant difference in plasma cytokines between the regular exercise (RE) and the sedentary control (SC) groups

Cytokines are essential components of the immune system and play an important role in initiating and regulating immune responses. IFN- $\gamma$, TNF- $\alpha$ and IL- 6 expression plays a central role in host defense. Thus, we first detected plasma levels of IFN- $\gamma$, TNF- $\alpha$ and IL- 6 . There were no significant differences in plasma levels of IFN- $\gamma$, TNF- $\alpha$ and IL- 6 between the $\mathrm{RE}$ and SC groups (Fig. 1A-C).

\section{Reduced frequencies of invariant natural killer T cells and NK cells in peripheral blood in the RE group}

It has been reported that exercise may induce changes in the proportion of peripheral blood mononuclear cell (PBMC) subsets $[18,19]$; thus we detected the frequencies of PBMC subsets to investigate the influence of regular exercise on immune cells. Flow cytometric analysis of $\mathrm{T}$ lymphocyte subpopulations including $\mathrm{CD}^{+} \mathrm{T}$ cells, $\mathrm{CD} 4^{+} \mathrm{T}$ cells, $\mathrm{CD}^{+} \mathrm{T}$ cells and Treg cells $\left(\mathrm{CD} 4{ }^{+} \mathrm{CD} 25^{\mathrm{hi}}\right)$ showed that there were no significant differences between the RE and SC groups (Fig. 2A-D). However, the frequency of invariant natural killer T (iNKT) cells in PBMC was significantly reduced in the RE group compared to that in the SC group (Fig. 2E). The frequency of NK cells in PBMC presented a similar trend to that for iNKT cells (Fig. 2F).

Increased levels of Th1 and Th2 cytokines secreted by PBMC in the RE group after HBcAg and S. pyogenes stimulation

To explore the immune responses against pathogen invasion, we determined the cytokine levels in the culture supernatants of hepatitis B core antigen (HBcAg) or heatinactivated Streptococcus pyogenes (S. pyogenes) stimulated PBMCs. Levels of Th1 (IFN- $\gamma$ and TNF- $\alpha$ ) and Th2 (IL-6) cytokines were increased in the RE group after HBcAg and heatinactivated S. pyogenes stimulation compared with those in the SC group (Fig. $3 \mathrm{~A}$ and B). These results suggested that a more effective immune response was induced to prevent pathogen invasion in the RE group.

Decreased cytokine production by PBMC after non-microbial exogenous antigen stimulation in the RE group

To determine the effects of regular exercise on the immune response to a series of antigen stimuli, we also investigated cytokine production following non-microbial antigen stimulation. In this study, we used iNKT cell activation ( $\alpha$-galactosylceramide, $\alpha$-GC) and pan-T cell stimulation (concanavalin A, ConA) as non-microbial antigen stimulation. The

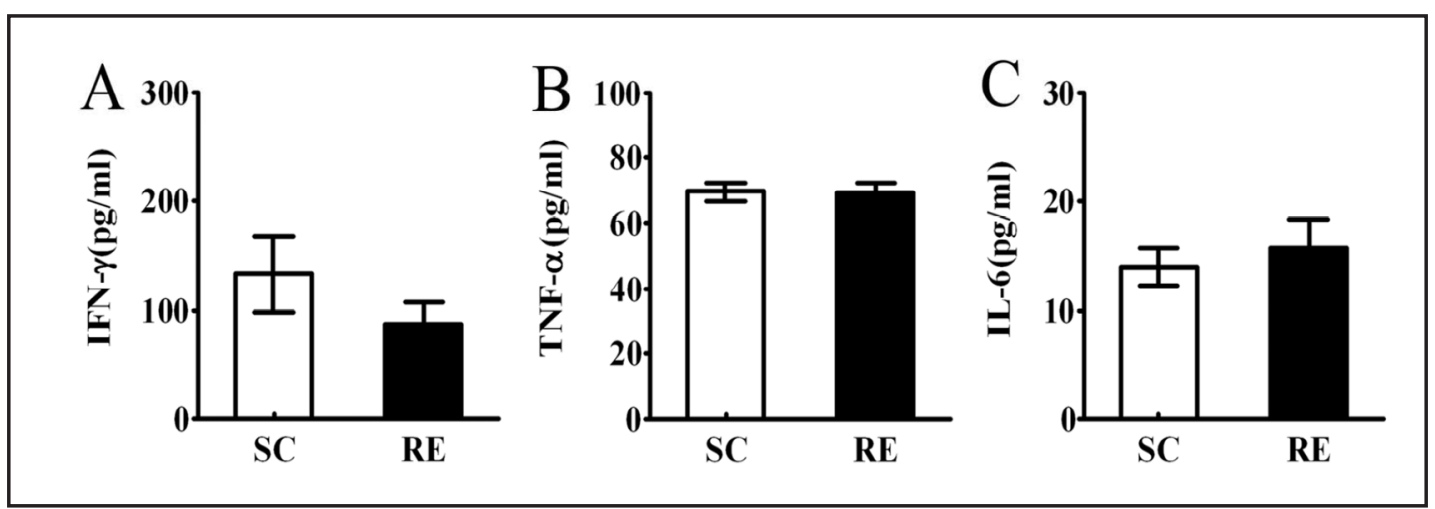

Fig. 1. Plasma cytokine levels in the RE and SC groups. Plasma levels of (A) IFN- $\gamma,(B)$ TNF- $\alpha$, and (C) IL-6 in the RE and SC groups were analyzed by ELISA. Data represent the mean \pm SD. 
Fig. 2. The frequencies of PBMC subsets in the RE and SC groups. The distribution of (A) $\mathrm{CD}^{+}$cells, (B) CD4+ cells, (C) CD8+ cells, (D) $\mathrm{CD} 4{ }^{+} \mathrm{CD} 25^{\mathrm{hi}} \mathrm{T}$ cells, (E) iNKT cells and (F) NK cells in the PBMC of the $\mathrm{RE}$ group were analyzed compared to those of the SC group by flow cytometry. Data represent the mean \pm SD. ${ }^{*}, P<0.05$. ***, $P<0.001$.

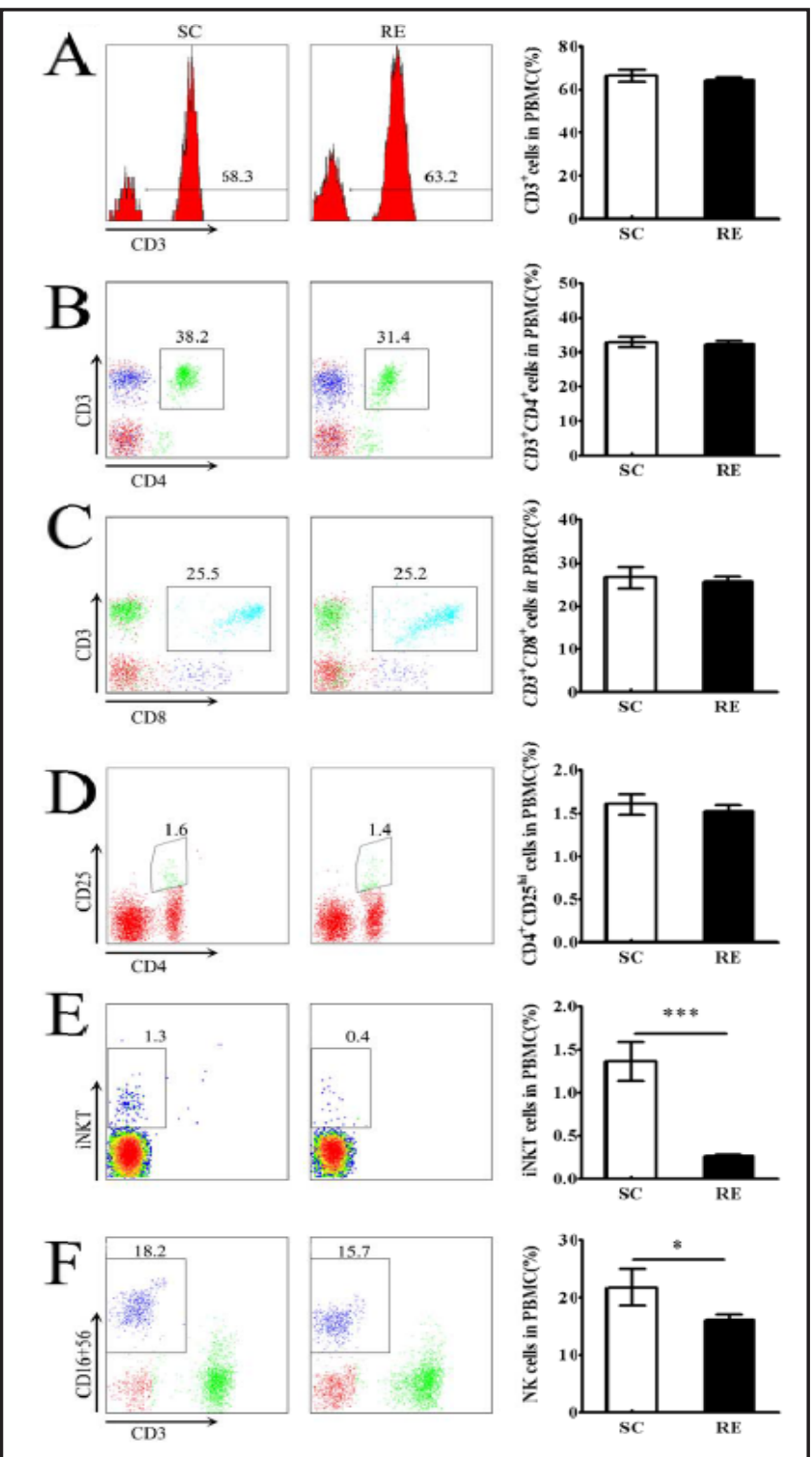

production of TNF- $\alpha$ and IL- 6 in response to $\alpha$-GC stimulation was reduced in the RE group compared with that in the SC group (Fig. 3C). However, there was no significant difference in the levels of IFN- $\gamma$ between the two groups (Fig. 3C). ConA was administered in PBMC cultures as a general stimulus of T cells [20]. After ConA stimulation, the levels of TNF- $\alpha$ and IL-6 were decreased in the RE group compared to those in the SC group, while no changes in IFN- $\gamma$ levels were observed (Fig. 3D).

Moreover, cytokine secretion by PBMC was observed in the absence of any stimulation. Consistent with the cytokine profiles after non-microbial antigen stimulation, in the absence of stimulation, the levels of TNF- $\alpha$ and IL- 6 were reduced in the RE group compared with those in the SC group, while there was no difference in the levels of IFN- $\gamma$ between the two groups (Fig. 3E). In addition, in both groups there was an upward trend in the levels of IFN- $\gamma$, TNF- $\alpha$ and IL- 6 after $\alpha$-GC stimulation. However, this did not reach statistical significance (Fig. 4A-C). These data suggest that, in the absence of microbial invasion, and therefore not at the stage of infectious burden, the cytokine production ability of the RE group is reduced compared with that of the SC group, which may account for the absence of excessive inflammatory reactions in the RE group. 


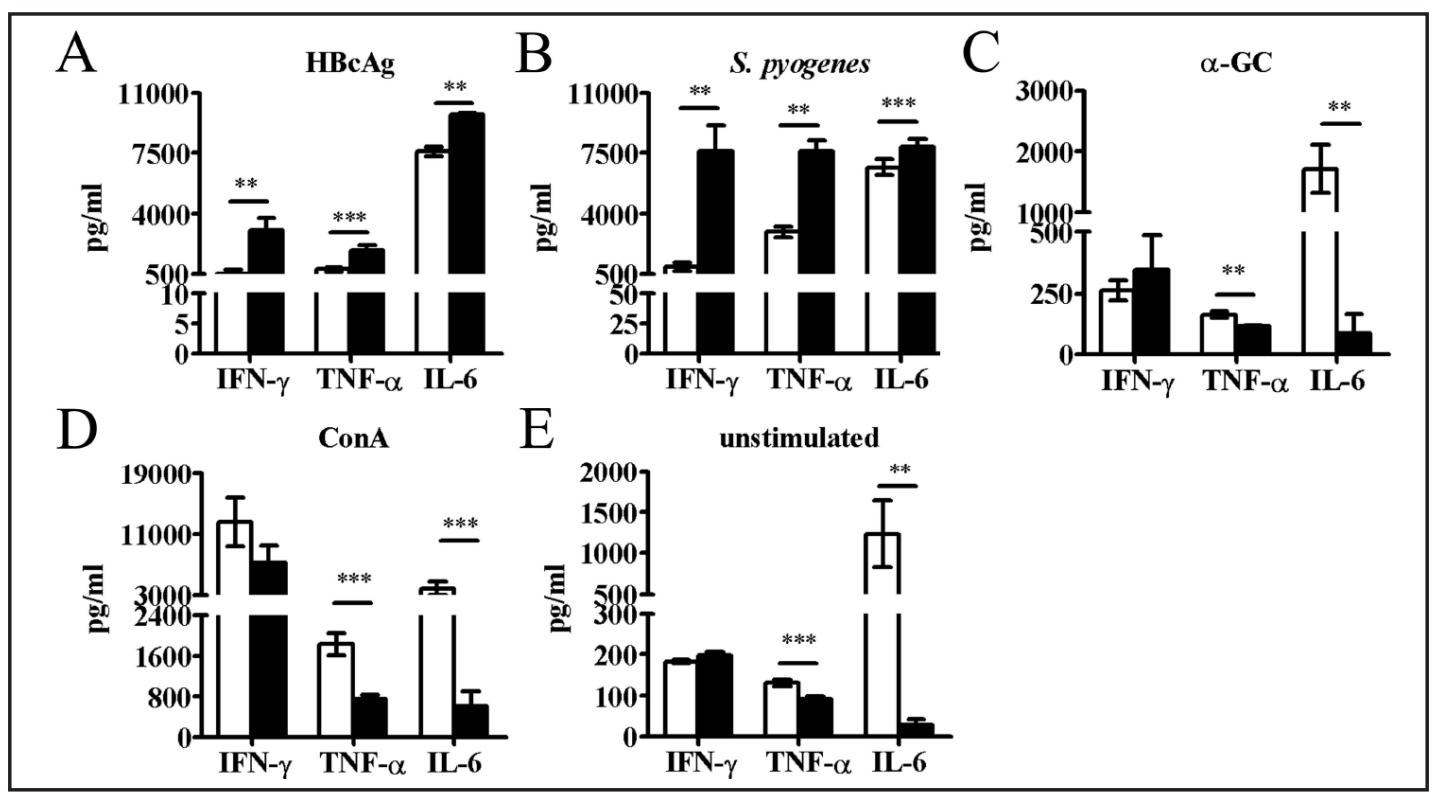

Fig. 3. In vitro analysis of cytokines secreted by PBMC after HBcAg, S. pyogenes, $\alpha-\mathrm{GC}$ and ConA stimulation. The levels of cytokines secreted by PBMC from the RE and SC groups stimulated in vitro with (A) HBcAg, (B) S. pyogenes (C) $\alpha-\mathrm{GC}$, (D) ConA and (E) without stimulation were analyzed by ELISA. Data represent the mean \pm SD. $* *, P<0.01$, ***, $P<0.001$.

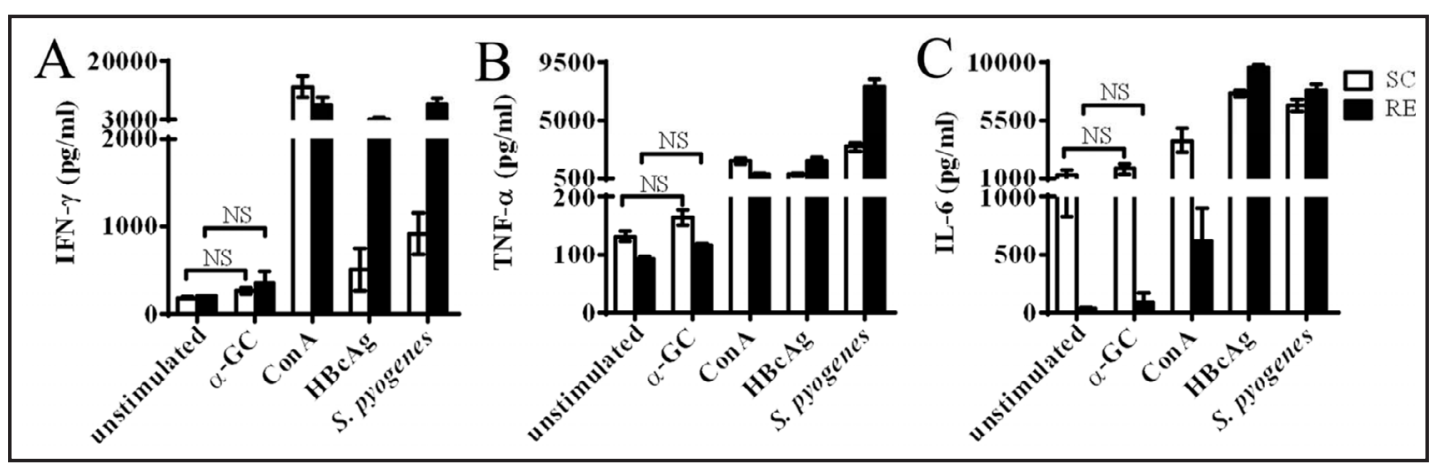

Fig. 4. Comparisons of cytokines levels secreted by PBMCs with or without stimulation. The levels of (A) IFN- $\gamma$, (B) TNF- $\alpha$ and (C) IL- 6 secreted by PBMCs with or without stimulation. Data represent the mean \pm SD. NS: no significant difference.

\section{Dendritic cell function in RE and SC groups}

Antigen presentation by antigen-presenting cells (APC) stimulates T cells to produce Th1 and Th2 cytokines. As dendritic cells (DC) are important APCs, we examined the frequency of this cell subset. There were no significant differences in the frequencies of DC subpopulations (BDCA- $1^{+}$DCs, BDCA-2 ${ }^{+}$Cs, and BDCA- ${ }^{+}$DCs) between the RE and SC groups (Fig. 5A).

To determine whether the function of DCs is changed in the RE group, we detected the production of IFN- $\alpha$ and IL-12 which are mainly produced by DCs. The levels of IFN- $\alpha$ and IL12 secreted by PBMC after HBcAg or S. pyogenes stimulation were increased in the RE group compared with those in the SC group (Fig. 5B), while there were no significant differences between the two groups in the secretion of IFN- $\alpha$ and IL-12 after ConA and $\alpha$-GC stimulation (Fig. 5C).

Increased expressions of TLRs in the RE group

APCs recognize pathogenic antigens by interacting with pathogen recognition receptors (PRR), which are highly expressed on immune cells [21]. Some antigens from Gram-positive 
Fig. 5. The frequencies of DC subsets and secretion of IFN- $\alpha$ and IL12 by PBMC after stimulation. (A) The distribution of BDCA- $1^{+}$cells, BDCA $-2^{+}$cells and BDCA- $3^{+}$cells in PBMC from the RE and SC groups was analyzed by flow cytometry. The levels of (B) IFN- $\alpha$ and (C) IL-12 secreted by PBMC from the RE and SC groups after in vitro stimulation were analyzed by ELISA. Data represent the mean \pm SD. *, $P<0.05$.

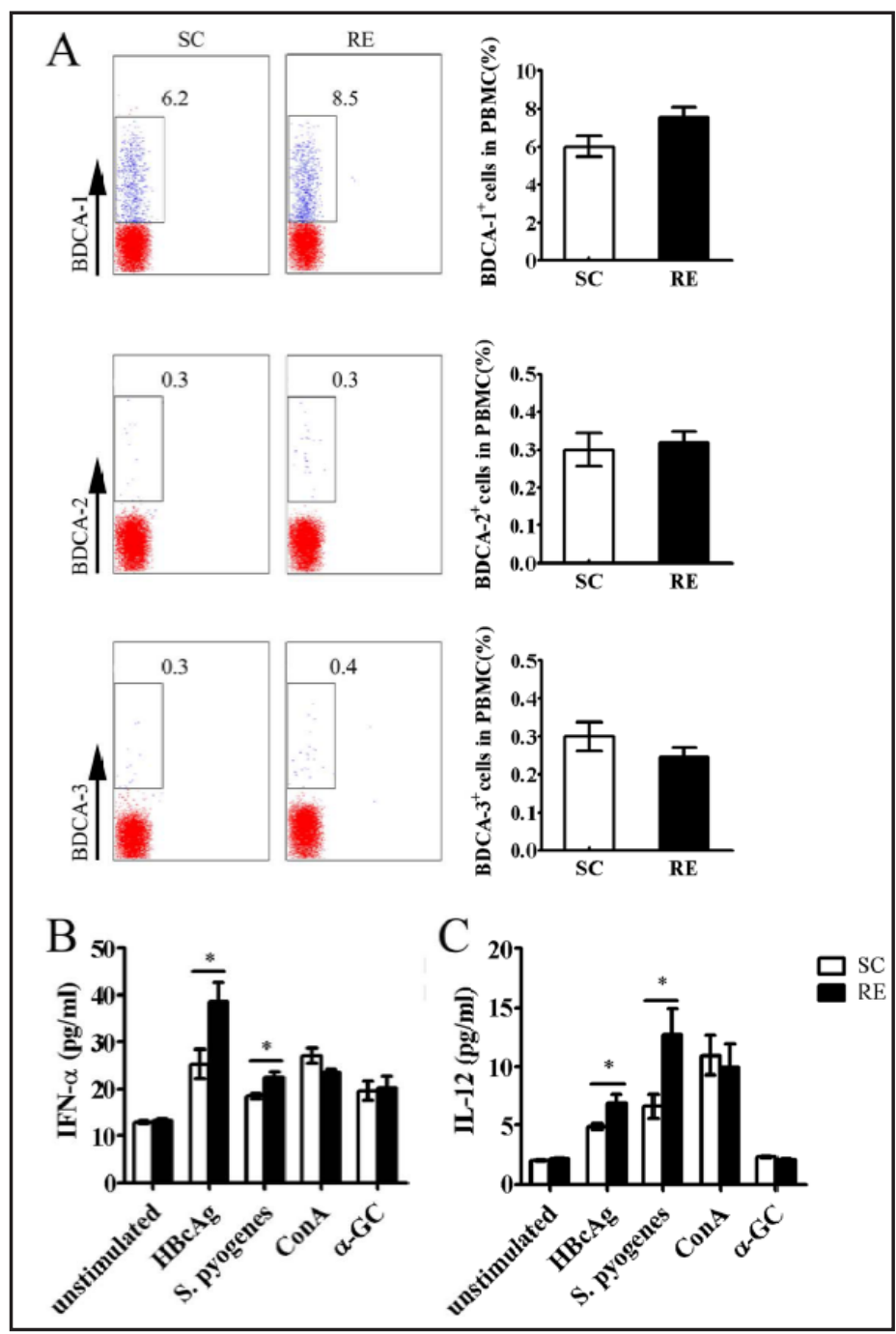

bacteria activate TLR2 signaling and induce antimicrobial peptide expression [22, 23]. Furthermore, the viral HBcAg activates TLR7 signaling and recruits heterologous T cells [24]. Thus, we next analyzed TLR2, TLR7, and MyD88 expression. We found that TLR2, TLR7 and MyD88 expression was significantly increased in the RE group compared with that in the SC group without any stimulation (Fig. 6A). Moreover, TLR2, TLR7 and MyD88 expression was elevated in the RE group compared with that in the SC group after HBcAg stimulation (Fig. 6B). Following S. pyogenes stimulation, TLR2 and MyD88 expression was significantly increased, while TLR7 expression was decreased in the RE group compared with that in the SC group (Fig. 6C). Furthermore, TLR7 expression was elevated in the RE group compared with that in the SC group, while no obvious differences were detected in the expression of TLR2 and MyD88 between the two groups after ConA or $\alpha$-GC stimulation (Fig. 6D and E, TLR signaling pathway molecule expression in the RE group following ConA or $\alpha$-GC stimulation.). In addition, analysis of the expression of TLR4, which is associated with Gram-negative bacterial invasion, revealed no significant differences between the RE and SC groups following stimulation with HBcAg, S. pyogenes, ConA or $\alpha$-GC (Fig. 6F, TLR4 expression in the RE group with or without stimulation with microbial antigens).

Th1 cells differentiation is dependent on STAT1-mediated signaling [25, 26], while STAT6 is required for development of Th2 cells [27]; therefore, we analyzed the expression of STAT1 and STAT6 in PBMC in response to different stimuli. STAT1 expression was significantly increased in the RE group compared with that in the SC group after both S. pyogenes and 


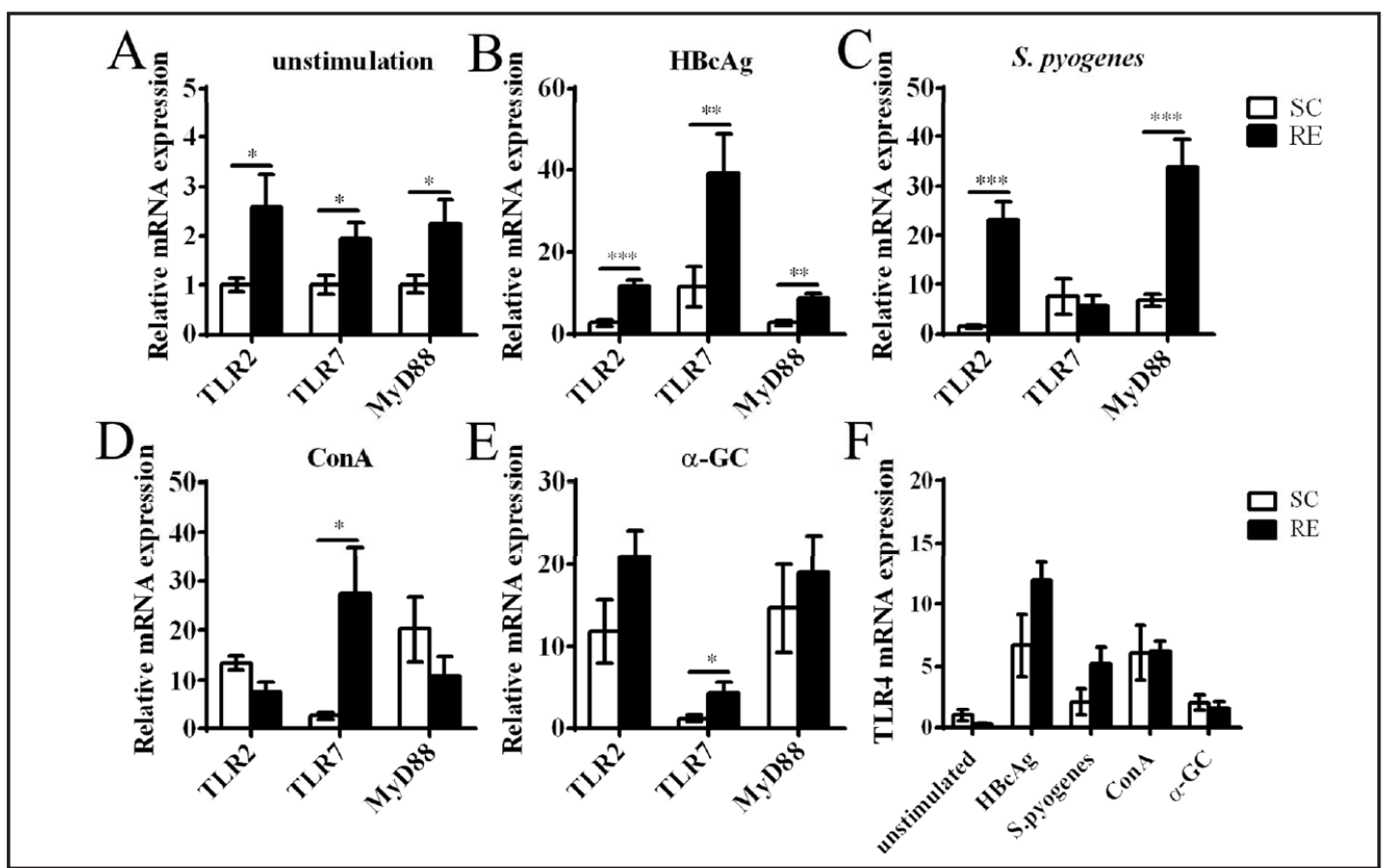

Fig. 6. TLR signaling pathway molecule expression with HBcAg, S. pyogenes, ConA and $\alpha$-GC stimulation. Real-time quantitative PCR analysis of TLR2, TLR7 and MyD88 mRNA expression levels in the RE group versus the SC group (A) without stimulation and stimulated with (B) HBcAg or (C) S. pyogenes, (D) ConA and (E) $\alpha$-GC. (F) The mRNA expression of TLR4 were detected in the RE group versus the SC group with or without stimulation. Data represent the mean $\pm \mathrm{SD}$. ${ }^{*}, P<0.05$, ${ }^{* *}, P<0.01,{ }^{* *}, P<0.001$.

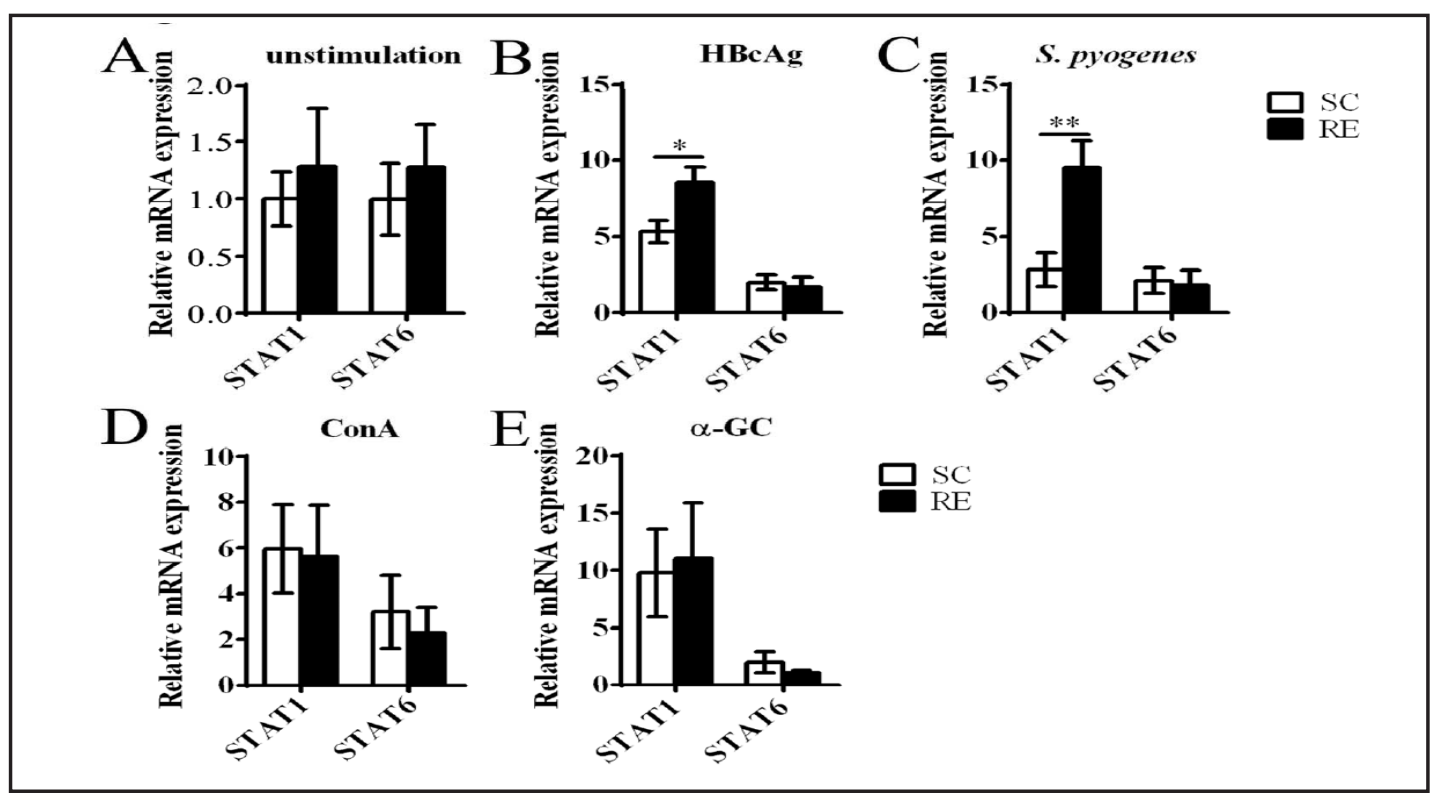

Fig. 7. STAT signaling pathway molecule expression with $\mathrm{HBcAg}$, S. pyogenes, ConA and $\alpha$-GC stimulation. The mRNA expression of STAT1 and STAT6 was detected in the RE group versus the SC group (A) without stimulation and stimulated with (B) HBcAg, (C) S. pyogenes, (D) ConA and (E) $\alpha$-GC stimulation. Data represent the mean \pm SD. ${ }^{*}, P<0.05, * *, P<0.01$.

HBcAg stimulation, while there were no obvious differences in STAT1 expression between the two groups without stimulation or after ConA or $\alpha$-GC stimulation (Fig. 7A-E, STAT1 signaling pathway molecule expression in the RE group following ConA or $\alpha$-GC stimulation). 


\section{Cellular Physiology Cell Physiol Biochem 2015;37:735-746 \begin{tabular}{l|l|l} 
DOI: 10.1159/000430391 & (C) 2015 S. Karger AG, Basel
\end{tabular} \begin{tabular}{l|l|} 
and Biochemistry Published online: September 11, 2015 & www.karger.com/cpb \\
\cline { 1 - 2 }
\end{tabular} \\ Zheng et al.: Regular Exercise Boosts Immunity to Microbes}

There were no significant differences in STAT6 expression between the two groups with or without stimulation (Fig. 7A-E, STAT6 signaling pathway molecule expression in the RE group following ConA or $\alpha$-GC stimulation).

\section{Discussion}

Some studies have indicated that endurance exercise provides an "open window" of increased susceptibility to infections, especially during the competition season $[7,28]$. Recently, a series of studies have demonstrated that regular moderate exercise can decrease the rate of upper respiratory tract infections [6] and that regular exercise can induce slight changes in the immune system [14, 29]; thus, indicating an immunomodulatory role for exercise $[15,30]$. However, the immune changes induced by regular exercise remain to be clarified. In this study, we recruited members of a university badminton club to investigate the effects of regular exercise on the immune responses induced by microbial stimuli.

First, we found that not only the proportions of iNKT and NK cells were reduced in the peripheral blood, but also cytokine secretion by PBMC was suppressed after $\alpha$-GC and ConA stimulation in the RE group compared with the SC group. Cytokines are essential components of the immune system and play an important role in initiating and regulating immune responses. In the early phase of infectious inflammation, IL- 6 is produced by monocytes and macrophages immediately after the stimulation of TLRs by distinct pathogenassociated molecular patterns (PAMPs) [31]. This acute IL-6 expression plays a central role in host defense by stimulating various cell populations. TNF- $\alpha$ is an important Th1-type cytokine required to eliminate antigens [32]. Low levels of TNF- $\alpha$ and IL- 6 after $\alpha$-GC and ConA stimulation indicated that regular moderate exercise induced the suppression of iNKT cell and T cell activation. Meanwhile, we compared the levels of cytokines secreted by PBMC with or without stimulation and found that, with the exception of stimulation with $\alpha-G C$, the levels of IFN- $\gamma$, TNF- $\alpha$ and IL- 6 were significantly increased after stimulation in both groups (Fig. 4). As $\alpha-G C$ is a prototypical activator of iNKT cells, we speculate that the low levels of cytokines secreted by PBMCs after $\alpha$-GC stimulation was a consequence of low numbers of iNKT cells in PBMCs. These observations provide evidence that regular exercise ameliorates inflammatory reactions by suppressing lymphocyte activation in a generalized state and not at the stage of infection. It can be speculated that this effect reduces the inflammation associated with hyper immune reactions, such as allergy and autoimmune disease.

In this study, we used HBcAg and S. pyogenes as microbial antigens to investigate the effect of physical training on the immune response to pathogenic infections. We found that the levels of IFN- $\gamma$, TNF- $\alpha$ and IL- 6 secreted by PBMC were increased in the RE group after $\mathrm{HBcAg}$ and $S$. pyogenes stimulation. Responses to HBcAg and $S$. pyogenes stimulation may be influenced by previous infection by hepatitis B virus or $S$. pyogenes. In order to control for this, we measured the titers of HBcAb and ASO in our volunteers. We found that titers to $\mathrm{HBcAb}$ were negative of them, probably as a consequence of universal HBV vaccination in China. Two subjects in each group had positive ASO titers ( $P=0.7397$, Table 1$)$. The levels of cytokines secreted by PBMCs and the mRNA expression level of the TLR signaling pathway molecules in both subjects in the RE group were higher than those in the two subjects in the SC group, except for TLR7, TLR4 and STAT6. These results were consistent with the trends in the two groups (Fig. 8). These data indicate that these antigens induce an enhanced Th1 and pro-inflammatory cytokine response. Antigen presentation by APCs is required for the activation of effector T cells by HBcAg and S. pyogenes [33, 34], Previous studies have demonstrated that plasmacytoid DCs are decreased in athletes after running a marathon, and that long-term intensive training may affect the function of innate immune cells, in particular, reducing their capacity to respond to acute challenges, and possibly contributing to an increased risk of infection [35, 36]. Moreover, IFN- $\alpha$ and IL-12 derived from DCs play an essential role in Th1 cell differentiation and protecting against pathogen invasion [37]. Thus, in this study, we analyzed the frequencies of DC subsets in peripheral blood. Although no differences were observed between the RE and HR groups, the levels of IFN- $\alpha$ and IL-12 in 
Fig. 8. Analysis of the ASO positive subjects in each group. The levels of cytokines secreted by PBMC in ASO positive subjects in the RE group versus the SC group with or without stimulation (A and B). Real-time quantitative PCR analysis of mRNA expression (C and D) secreted by PBMC with or without stimulation in the RE group versus the SC group. Each point represents an individual ASO positive subject.

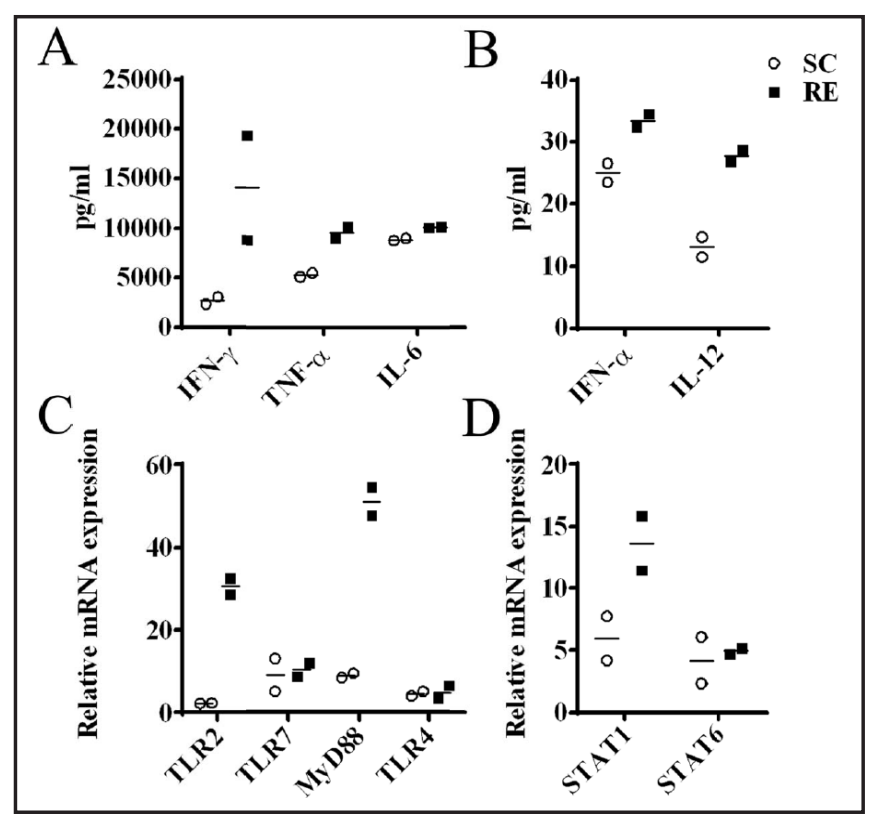

culture supernatants of PBMC stimulated in vitro with S. pyogenes or HBcAg were increased in the RE group compared with the SC group. However, no obvious differences were observed between the two groups following $\alpha-\mathrm{GC}$ and ConA stimulation. Increased levels of IFN- $\alpha$ and IL-12 could significantly enhance the T cell response against pathogens.

TLRs are key sensors of bacteria, viruses, fungi and protozoa [38]. A series of studies have suggested that some antigens from Gram-positive bacteria activate TLR2 signaling and induce antimicrobial peptide expression [22, 23] Also, HBcAg activates TLR7 signaling and recruits heterologous T cells [24]. Individual TLR signaling pathways are divergent, although the MyD88 signaling pathway is common to most TLRs. MyD88-deficient mice do not produce inflammatory cytokines such as TNF- $\alpha$ and IL-12p40 in response to stimulation by any of the TLR ligands[39]. Thus, in our subsequent examination of the expression of TLR2, TLR7 and MyD88, we found that expression of all three was significantly increased in the RE group with or without microbial antigen stimulation. The increased expression of TLRs could activate T cells via DC intrinsic and extrinsic mechanisms [40], which further confirms regular exercise induces a more effective immune response to prevent pathogen invasion.

In conclusion, we evaluated the changes in immune responses to microbial antigens induced by regular moderate exercise. In the absence of infection, the proportion of NKT and NK cells was decreased, and their activation was suppressed. These observations indicate a generalized suppression of inflammatory lymphocyte activation following regular exercise. However, regular exercise enhances the response to pathogen invasion through upregulation of the antigen-presenting function of DCs via the TLR signaling pathway. This process activates effector cells to produce substantial amounts of cytokines, which may enhance resistance to the invasion of infectious pathogens. We propose that this mechanism, to some extent, explains why regular exercise enhances resistance to pathogen invasion.

\section{Acknowledgements}

The authors would like to acknowledge the generous participation of all athletes and healthy sedentary college students in this research study. This work was supported by the National Natural Science Foundation of China (No. 81271810), the Doctoral Fund of Ministry of Education of China (20120101110009). 


\section{Cellular Physiology Cell Physiol Biochem 2015;37:735-746 \begin{tabular}{l|l|l} 
DOI: 10.1159/000430391 & (C) 2015 S. Karger AG, Basel
\end{tabular} www.karger.com/cpb \\ Zheng et al.: Regular Exercise Boosts Immunity to Microbes}

\section{Disclosure Statement}

The authors declare that they have no conflict of interest.

\section{References}

1 Waxman A: Who global strategy on diet, physical activity and health. Food Nutr Bull 2004;25:292-302.

2 Engstrom G, Hedblad B, Janzon L: Hypertensive men who exercise regularly have lower rate of cardiovascular mortality. J Hypertens 1999;17:737-742.

3 Melo SF, Fernandes T, Barauna VG, Matos KC, Santos AA, Tucci PJ, Oliveira EM: Expression of microrna-29 and collagen in cardiac muscle after swimming training in myocardial-infarcted rats. Cell Physiol Biochem 2014;33:657-669.

4 Gomes RM, Tofolo LP, Rinaldi W, Scomparin DX, Grassiolli S, Barella LF, de Oliveira JC, Branco RC, Agostinho AR, Ribeiro TA, Gravena C, Mathias PC: Moderate exercise restores pancreatic beta-cell function and autonomic nervous system activity in obese rats induced by high-fat diet. Cell Physiol Biochem 2013;32:310-321.

5 Leite Nde C, Ferreira TR, Rickli S, Borck PC, Mathias PC, Emilio HR, Grassiolli S: Glycolytic and mitochondrial metabolism in pancreatic islets from msg-treated obese rats subjected to swimming training. Cell Physiol Biochem 2013;31:242-256.

6 Nieman DC, Nehlsen-Cannarella SL, Markoff PA, Balk-Lamberton AJ, Yang H, Chritton DB, Lee JW, Arabatzis $\mathrm{K}$ : The effects of moderate exercise training on natural killer cells and acute upper respiratory tract infections. Int J Sports Med 1990;11:467-473.

7 Robson-Ansley P, Howatson G, Tallent J, Mitcheson K, Walshe I, Toms C, G DUT, Smith M, Ansley L: Prevalence of allergy and upper respiratory tract symptoms in runners of the london marathon. Med Sci Sports Exerc 2012;44:999-1004.

8 Kruijsen-Jaarsma M, Revesz D, Bierings MB, Buffart LM, Takken T: Effects of exercise on immune function in patients with cancer: A systematic review. Exerc Immunol Rev 2013;19:120-143.

9 Xiong Y, Li Y, Xiong Y, Zhao Y, Tang F, Wang X: Exhaustive running exercise induce tyrosine phosphorylation of band 3 in rat erythrocytes. Cell Physiol Biochem 2013;32:1060-1071.

10 Nieman DC: Marathon training and immune function. Sports Med 2007;37:412-415.

11 Nieman DC, Konrad M, Henson DA, Kennerly K, Shanely RA, Wallner-Liebmann SJ: Variance in the acute inflammatory response to prolonged cycling is linked to exercise intensity. J Interferon Cytokine Res 2012;32:12-17.

12 Ronsen O, Pedersen BK, Oritsland TR, Bahr R, Kjeldsen-Kragh J: Leukocyte counts and lymphocyte responsiveness associated with repeated bouts of strenuous endurance exercise. J Appl Physiol 2001;91:425-434.

13 Campos JC, Gomes KM, Ferreira JC: Impact of exercise training on redox signaling in cardiovascular diseases. Food Chem Toxicol 2013;62:107-119.

14 Yan H, Kuroiwa A, Tanaka H, Shindo M, Kiyonaga A, Nagayama A: Effect of moderate exercise on immune senescence in men. Eur J Appl Physiol 2001;86:105-111.

15 Walsh NP, Gleeson M, Shephard RJ, Woods JA, Bishop NC, Fleshner M, Green C, Pedersen BK, Hoffman-Goetz L, Rogers CJ, Northoff H, Abbasi A, Simon P: Position statement. Part one: Immune function and exercise. Exerc Immunol Rev 2011;17:6-63.

16 Nieman DC, Henson DA, Austin MD, Sha W: Upper respiratory tract infection is reduced in physically fit and active adults. Br J Sports Med 2011;45:987-992.

17 Diao H, Kohanawa M: Endogenous interleukin-6 plays a crucial protective role in streptococcal toxic shock syndrome via suppression of tumor necrosis factor alpha production. Infect Immun 2005;73:3745-3748.

18 Prestes J, de Ferreira CK, Dias R, Frollini AB, Donatto FF, Cury-Boaventura MF, Guereschi MG, PithonCuri TC, Verlengia R, Palanch AC, Curi R, Cavaglieri CR: Lymphocyte and cytokines after short periods of exercise. Int J Sports Med 2008;29:1010-1014.

19 Navalta JW, McFarlin BK, Lyons S, Arnett SW, Schafer MA: Cognitive awareness of carbohydrate intake does not alter exercise-induced lymphocyte apoptosis. Clinics (Sao Paulo) 2011;66:197-202. 


\section{Cellular Physiology Cell Physiol Biochem 2015;37:735-746 \begin{tabular}{l|l} 
DOI: 10.1159/000430391 & (C) 2015 S. Karger AG, Basel
\end{tabular} and Biochemistry Published online: September 11, $2015 \quad$ www.karger.com/cpb \\ Zheng et al.: Regular Exercise Boosts Immunity to Microbes}

20 Bulau AM, Fink M, Maucksch C, Kappler R, Mayr D, Wagner K, Bufler P: In vivo expression of interleukin-37 reduces local and systemic inflammation in concanavalin a-induced hepatitis. ScientificWorldJournal 2011;11:2480-2490.

21 Ahmad R, Shihab PK, Jasem S, Behbehani K: Fsl-1 induces mmp-9 production through tlr-2 and nf-kappab / ap-1 signaling pathways in monocytic thp-1 cells. Cell Physiol Biochem 2014;34:929-942.

22 Zaman M, Abdel-Aal AB, Fujita Y, Phillipps KS, Batzloff MR, Good MF, Toth I: Immunological evaluation of lipopeptide group a streptococcus (gas) vaccine: Structure-activity relationship. PLoS One 2012;7:e30146.

23 Lai Y, Cogen AL, Radek KA, Park HJ, Macleod DT, Leichtle A, Ryan AF, Di Nardo A, Gallo RL: Activation of tlr2 by a small molecule produced by staphylococcus epidermidis increases antimicrobial defense against bacterial skin infections. J Invest Dermatol 2010;130:2211-2221.

24 Chen A, Ahlen G, Brenndorfer ED, Brass A, Holmstrom F, Chen M, Soderholm J, Milich DR, Frelin L, Sallberg M: Heterologous t cells can help restore function in dysfunctional hepatitis c virus nonstructural 3/4a-specific t cells during therapeutic vaccination. J Immunol 2011;186:5107-5118.

25 Robinson DS, O'Garra A: Further checkpoints in th1 development. Immunity 2002;16:755-758.

26 Takeda A, Hamano S, Yamanaka A, Hanada T, Ishibashi T, Mak TW, Yoshimura A, Yoshida H: Cutting edge: Role of il-27/wsx-1 signaling for induction of t-bet through activation of stat1 during initial th1 commitment. J Immunol 2003;170:4886-4890.

27 Kaplan MH, Schindler U, Smiley ST, Grusby MJ: Stat6 is required for mediating responses to il-4 and for development of th2 cells. Immunity 1996;4:313-319.

28 Kakanis MW, Peake J, Brenu EW, Simmonds M, Gray B, Hooper SL, Marshall-Gradisnik SM: The open window of susceptibility to infection after acute exercise in healthy young male elite athletes. Exerc Immunol Rev 2010;16:119-137.

29 Speaker KJ, Cox SS, Paton MM, Serebrakian A, Maslanik T, Greenwood BN, Fleshner M: Six weeks of voluntary wheel running modulates inflammatory protein (mcp-1, il-6, and il-10) and damp (hsp72) responses to acute stress in white adipose tissue of lean rats. Brain Behav Immun 2014;39:87-98.

30 de Araujo CC, Silva JD, Samary CS, Guimaraes IH, Marques PS, Oliveira GP, do Carmo LG, Goldenberg RC, Bakker-Abreu I, Diaz BL, Rocha NN, Capelozzi VL, Pelosi P, Rocco PR: Regular and moderate exercise before experimental sepsis reduces the risk of lung and distal organ injury. J Appl Physiol (1985) 2012;112:12061214.

31 Janeway CA, Jr., Medzhitov R: Innate immune recognition. Annu Rev Immunol 2002;20:197-216.

32 Agudelo 0, Bueno J, Villa A, Maestre A: High ifn-gamma and tnf production by peripheral nk cells of colombian patients with different clinical presentation of plasmodium falciparum. Malar J 2012;11:38.

33 Milich DR, Chen M, Schodel F, Peterson DL, Jones JE, Hughes JL: Role of b cells in antigen presentation of the hepatitis b core. Proc Natl Acad Sci U S A 1997;94:14648-14653.

34 Ganem MB, De Marzi MC, Fernandez-Lynch MJ, Jancic C, Vermeulen M, Geffner J, Mariuzza RA, Fernandez MM, Malchiodi EL: Uptake and intracellular trafficking of superantigens in dendritic cells. PLoS One 2013;8:e66244.

35 Nickel T, Emslander I, Sisic Z, David R, Schmaderer C, Marx N, Schmidt-Trucksass A, Hoster E, Halle M, Weis M, Hanssen H: Modulation of dendritic cells and toll-like receptors by marathon running. Eur J Appl Physiol 2012;112:1699-1708.

36 Morgado JM, Rama L, Silva I, de Jesus Inacio M, Henriques A, Laranjeira P, Pedreiro S, Rosado F, Alves F, Gleeson M, Pais ML, Paiva A, Teixeira AM: Cytokine production by monocytes, neutrophils, and dendritic cells is hampered by long-term intensive training in elite swimmers. Eur J Appl Physiol 2012;112:471-482.

37 Farkas A, Kemeny L: Interferon-alpha in the generation of monocyte-derived dendritic cells: Recent advances and implications for dermatology. Br J Dermatol 2011;165:247-254.

38 O'Neill LA: How toll-like receptors signal: What we know and what we don't know. Curr Opin Immunol 2006;18:3-9.

39 Hemmi H, Kaisho T, Takeuchi O, Sato S, Sanjo H, Hoshino K, Horiuchi T, Tomizawa H, Takeda K, Akira S: Small anti-viral compounds activate immune cells via the tlr7 myd88-dependent signaling pathway. Nat Immunol 2002;3:196-200.

40 Hou B, Reizis B, DeFranco AL: Toll-like receptors activate innate and adaptive immunity by using dendritic cell-intrinsic and -extrinsic mechanisms. Immunity 2008;29:272-282. 